\title{
PERFIL SOCIODEMOGRÁFICO DO PACIENTE ACOMETIDO POR SÍNDROME RESPIRATÓRIA AGUDA GRAVE: UM ESTUDO RETROSPECTIVO DE NOVE ANOS
}

\section{SOCIO-DEMOGRAPHIC PROFILE OF PACIENTS AFFECTED BY SEVERE ACUTE RESPIRATORY INFECTION: A NINE-YEARS RETROSPECTIVE STUDY}

\author{
Grazielle Pangratz Bedretchuk ${ }^{1 *}$, Ana Paula Hubie Sakr², Luciana Osório Cavalli3 \\ ${ }^{1}$ Estudante de Medicina do Centro Universitário da Fundação Assis Gurgacz. ${ }^{2}$ Graduação em \\ Medicina, Mestre em Ensino nas Ciências da Saúde pela Faculdades Pequeno Princípe; Docente do \\ Centro Universitário da Fundação Assis Gurgacz. ${ }^{3}$ Graduação em Medicina, Mestre pelo programa \\ de Biociências e Saúde, Linha de Práticas e Políticas de Saúde pela Universidade do Oeste do \\ Paraná, Docente Centro Universitário da Fundação Assis Gurgacz. \\ *Autor correspondente: graziellepb@outlook.com; https://orcid.org/0000-0002-4388-8041
}

\begin{abstract}
RESUMO
Introdução: A pandemia de 2009 foi causada pelo vírus influenza A(H1N1)pdm09, assim o Ministério da Saúde iniciou a notificação compulsória obrigatória de casos suspeitos e confirmados de Influenza, em 2013 foi iniciada a notificação dos casos de Síndrome Respiratória Aguda Grave. Objetivo: avaliar o perfil do paciente acometido com SRAG. Materiais e métodos: avaliar notificações feitas ao Sistema de Informação de Agravos de Notificação (SINAN) do munícipio de Cascavel - Paraná, durante os anos de 2009 a 2017. As variáveis estudadas foram: idade; sexo; vacina; fatores de risco; antiviral; diagnóstico etiológico; evolução clínica. Resultados: 53\% eram do sexo feminino. A média de idade foi 37,2 anos. $72 \%$ não receberam vacina. $88 \%$ apresentaram tosse. Pneumopatia foi a comorbidade mais frequente, em $6,09 \%$. Fizeram uso de Oseltamivir $76 \%$. $52,4 \%$ dos casos foram causados pelo vírus Influenza A. 4\% foram a óbito por SRAG. Conclusões: o perfil do paciente acometido pela SRAG em Cascavel, durante os nove anos de estudo, seria: sexo feminino, de até 40 anos, não imunizado contra a gripe, tosse como principal sintoma e pneumopata crônico.
\end{abstract}

Palavras-chave: epidemiologia, Influenza, vigilância epidemiológica.

\begin{abstract}
Introduction: The pandemic of 2009 was caused by influenza virus $A(H 1 N 1) p d m 09$, herewith it came the need of notify this cases. In 2009 the Ministry of Health began the mandatory notification of suspected and confirmed influenza cases. In 2013 the Brazilian Ministry of Health changed the definition for mandatory notification to suspected or confirmed cases of Severe Acute Respiratory Infection (SARI). Objective: evaluate the profile of patients with SARI. Materials and methods: evaluate the notifications made in the national surveillance information system of notifiable diseases (SINAN) with regard to the municipality of Cascavel-Paraná, during the years of 2009 to 2017. The studied variables was: age; sex; flu's vacine in the last 12 months; risk factors; antiviral use; etiological diagnosis; clinical evolution. Results: $53 \%$ of the cases were women. The average age was 37,2 years. $72 \%$ of the sample did not receive the vaccine. Chronic respiratory condition was the comorbidity more frequent, with $6,09 \%$. Oseltamivir was used by $76 \% .52,4 \%$ of the cases was caused
\end{abstract}


by the influenza A virus. SARI caused the death of $4 \%$ of all cases. Conclusions: the profile of the pacient affected by SARI in Cascavel, during the 9 years of study, would be female, younger than 40 years old, who was not immunized against the influenza, presenting cough as main symptom, paying attention to chronic respiratory conditions. Keywords: epidemiology, Influenza, epidemiological surveillance.

\section{INTRODUÇÃO}

A gripe sempre esteve presente no cenário mundial, porém em $2009 \mathrm{com}$ a pandemia causada pelo vírus $\mathrm{A} / \mathrm{H} 1 \mathrm{~N} 1$ novos olhares se voltaram a ela. $\mathrm{O}$ vírus foi primariamente identificado no sul dos estados Unidos, em abril de 2009 (PUNPANICH e CHOTPITAYASUNONDH, 2012). Este vírus foi resultado de um evento genético onde houve a recombinação genética entre vírus suíno, aviário e humano, com um imenso potencial de disseminação entre os humanos (MINISTÉRIO DA SAÚDE, 2015). O vírus influenza possui RNA de hélice única, e três tipo: $A, B$ e $C$. O tipo $A$, regularmente, sofre modificações em seu genoma e é o responsável pela maioria dos processos epidêmicos (FELINTO et al, 2019).

Chamada inicialmente de gripe suína e posteriormente de gripe $A$, em abril de 2009 a Organização Mundial de Saúde (OMS) declarou que a epidemia era um caso de emergência internacional de saúde pública, fazendo-se necessário que a vigilância em relação a disseminação do vírus fosse intensificada (SHUELTER-TREVISOL et al 2012). Em junho do mesmo ano, a OMS declarou estado de pandemia, quando a transmissão já havia sido documentada em mais de 70 países (PUNPANICH e CHOTPITAYASUNONDH, 2012).

Assim como na pandemia por gripe espanhola, em 1918, a morbimortalidade na pandemia de 2009 também foi maior em pacientes adultos jovens. Quando uma pandemia causada por influenza eclode, normalmente ela causará uma maior disseminação da doença e morte, isso foi visto no século $20 \mathrm{com}$ a gripe espanhola, a qual vitimou em torno de 60 milhões de pessoas, e pode-se notar a mesma tendência em 2009. Logo no começo da primeira onda da pandemia, o potencial de virulência de um novo tipo causa muita preocupação na população, governantes e profissionais da saúde (KHANDAKER et al, 2012)

Com o aumento da repercussão a respeito dos casos de influenza no mundo e no Brasil, surgiu a necessidade de uma vigilância maior e mais cuidadosa desse agravo. É de extrema importância saber qual grupo social vem sendo mais acometido, para então serem tomadas atitudes na esfera da saúde pública na tentativa de minimizar danos e o número de casos com desfechos desfavoráveis.

Então, desde a pandemia de influenza pelo vírus A (H1N1) em 2009, tornou-se obrigatória a notificação universal de casos hospitalizados e óbitos em decorrência da Síndrome Respiratória Aguda Grave (SRAG) relacionados à influenza. No Brasil essas notificações são feitas ao Sistema de Informação de Agravos e Notificações (SINAN) (MINISTÉRIO DA SAÚDE, 2015).

Os casos que devem ser notificados devem apresentar o indivíduo hospitalizado com febre (mesmo que referida), acompanhada de tosse ou dor de garganta, apresentando dispneia ou saturação de $\mathrm{O}_{2}<95 \%$ ou desconforto respiratório. Também devem ser notificados, além dos pacientes hospitalizados com as características antes citadas, os óbitos causados por SRAG independentes da hospitalização (MINISTÉRIO DA SAÚDE, 2018).

A atenção primária tem como uma de suas ações a vacinação contra a influenza para determinados grupos de risco, é imperativo a avaliação dessas 
atitudes, para comprovar-se a real efetividade delas. A vacina protege contra as complicações associadas à Influenza. Desde 1999 o Ministério da Saúde disponibiliza a vacina sazonal para a faixa etária de 65 anos, em 2000 passou a disponibilizar para os indivíduos acima dos 60 anos de idade. Em 2010, os grupos prioritários entraram para essa lista. 2011 teve a inclusão de gestantes e crianças de seis meses até os dois anos. Em 2012 eram vacinadas as populações maiores de 60 anos, trabalhadores de saúde, crianças de seis meses a menos de dois anos, gestantes e povos indígenas (MINISTÉRIO DA SAÚDE, 2012). A única alteração foi a inclusão de crianças menores de seis anos na campanha de 2019 (BOGAZ, 2019).

Assim, este estudo se justifica uma vez que busca avaliar o perfil do paciente acometido com SRAG na cidade de Cascavel-PR, entre os anos de 2009 e 2017. Bem como investigar qual a faixa etária e sexo mais acometido; relacionar os casos de SRAG com a vacina para influenza; descrever os principais sinais e sintomas dos pacientes; analisar os fatores de risco; avaliar o uso de antivirais; discriminar quais foram os principais agentes etiológicos e observaram qual foi o desfecho dos casos estudados.

O objetivo deste artigo é identificar o perfil epidemiológico e sociodemográfico do paciente internado ou que foi a óbito em consequência da Síndrome Respiratória Aguda Grave; investigar qual a faixa etária mais acometida, assim como o sexo. Relacionar os casos de SRAG com a vacina para Influenza. Descrever os principais sinais e sintomas dos pacientes, e seus fatores de risco. Analisar o uso de antivirais, os principais agentes etiológicos e qual foi o desfecho dos casos observados.

\section{METODOLOGIA}

A pesquisa teve caráter descritivo na qual foram ser observados os dados coletados junto à vigilância epidemiológica no município de Cascavel, Estado do Paraná, notificados ao Sistema de Informação de Agravos de Notificação (SINAN), durante os anos de 2009 a 2017. A população do munícipio segundo o último censo feito pelo Instituto Brasileiro de Geografia e Estatística (IBGE) em 2010 era de 286.205 habitantes.

As informações contidas nas Fichas de Notificação foram agrupadas em tabelas no formato Excel, divididas por ano. A partir da série histórica, os seguintes dados foram coletados: idade; sexo; recebeu vacina contra gripe nos últimos 12 meses; principais sinais e sintomas; fatores de risco; uso de antiviral; diagnóstico etiológico; evolução clínica.

Com a obtenção destas informações gráficos e tabelas foram construídos para que os dados fossem analisados.

O Projeto de Pesquisa desse estudo foi submetido ao Comitê de Ética em Pesquisa com Seres Humanos do Centro Universitário Fundação Assis Gurgacz e aprovado sob o CAAE nº 03873018.2.0000.5219.

\section{RESULTADOS}

As fichas de notificação analisadas referentes aos anos de 2009 a 2017, totalizaram um número de 6456 pacientes notificados. Durante os anos de 2009 a 2012 as fichas de notificação eram referentes aos casos de Influenza Humana por Novo Subtipo (Pandêmico), a partir de 2013 que foi iniciada a notificação dos casos de SRAG. 
Em 2009, ano da pandemia, o número de casos foi de 5249, nos anos posteriores os números não foram maiores do que 300 casos. Em 2010 teve-se 171 notificações, 2011 foram apenas 22, já em 2012 houve um aumento nos números chegando a 196 casos. A alta continuou no próximo ano, e em 2013 acabaram sendo notificados 272 casos. 2014 houve uma queda nos números, sendo 126 casos. 95 casos no ano de 2015, e novamente uma alta no ano subsequente, atingindo 205 notificações em 2016. Em 2017 foram notificados 120 casos.

O sexo feminino é responsável por $53 \%$ dos casos, e o sexo masculino corresponde $47 \%$ das fichas avaliadas. A média de idade dos pacientes foi de 37,2 anos, variando a média, dos anos estudados, entre 25,6 anos e 51,5 anos.

A quantidade de pacientes que receberam vacina totaliza $756(12 \%)$, o número de pacientes que não receberam vacina é de 4585 (71\%) e 1115 (17\%) não foi informado.

Os sintomas descritos na ficha de notificação de 2009 a 2012, e os sintomas das fichas a partir de 2013 tiveram algumas mudanças. De 2009 a 2012 a ficha de notificação era a partir de caso suspeito de influenza humana por novo subtipo (pandêmico), nessa ficha os sinais e sintomas a serem observados eram: febre, tosse, calafrio, dispneia, dor de garganta, artralgia, mialgia, conjuntivite, coriza, diarreia e outros. A partir de 2013, começaram a ser notificados os casos de Síndrome Respiratória Aguda Grave, aqui os seguintes sintomas são observados: febre, desconforto respiratório, tosse, dor de garganta, dispneia, mialgia, saturação de $\mathrm{O}_{2}<$ $95 \%$ e outros.

Entre os sintomas tosse teve a maior incidência entre todos com $88 \%$ de acometimento. Em segundo lugar a febre foi mais incidente com $85 \%$. Mialgia esteve presente em $59 \%$ dos casos. Dor de garganta foi relatada em $54 \%$ dos casos. $51 \%$ das fichas analisadas demonstraram dispneia. Calafrio teve uma prevalência de $51 \%$. Os seguintes sintomas foram incluídos como outros na tabela apresentada: coriza (48\%); artralgia (34\%); desconforto respiratório (10\%); diarreia (10\%); conjuntivite $(9 \%)$; saturação de $\mathrm{O}_{2}<95 \%(7 \%)$; e os que já haviam sido considerados como outros $(45 \%)$.

Nas fichas de notificação de 2009 a 2012 os fatores de risco eram considerados como comorbidades, sendo eles: cardiopatia crônica, pneumopatia crônica, renal crônico, hemoglobinopatia, imunodeprimido, tabagismo, doença metabólica crônica e outros. A partir de 2013 os seguintes itens passaram a ser considerados como fatores de risco: pneumopatias crônicas, doença neurológica crônica, puerpério (até 42 dias do parto), doença cardiovascular crônica, doença renal crônicas, obesidade, imunodeficiência/imunodepressão, síndrome de Down, doença hepática crônica, Diabetes Mellitus, e outros.

O fator de risco mais prevalente nos pacientes acometidos pela SRAG é a Pneumopatia, presente em 6,09\% dos casos. Seguido pelo tabagismo, com incidência de $5,65 \%$. A cardiopatia é fator de risco para $5,22 \%$ da população estudada. $2,26 \%$ dos pacientes possuem doença metabólica crônica. 2,04\% possuem imunodepressão. A doença renal está presente em 1,07\% dos pacientes. Na tabela apresentada dentro do item "Outros" está incluso: doença neurológica $(0,96 \%)$; obesidade $(0,77 \%)$; hemoglobinopatias $(0,28 \%)$; síndrome de Down $(0,12 \%)$; doença hepática $(0,11 \%)$; puerpério $(0,03 \%)$; e aqueles que já era classificados como outros $(17,55 \%)$. 
Tabela 1. Principais sinais e sintomas

\begin{tabular}{|c|c|c|c|c|c|c|c|c|c|c|c|}
\hline & 2009 & 2010 & 2011 & 2012 & 2013 & 2014 & 2015 & 2016 & 2017 & Total & $\%$ \\
\hline \multicolumn{12}{|c|}{ Febre } \\
\hline Sim & 4590 & 144 & 20 & 156 & 193 & 113 & 75 & 105 & 98 & 5494 & $85 \%$ \\
\hline & 636 & 26 & 2 & 40 & 76 & 12 & 17 & 48 & 20 & 877 & $14 \%$ \\
\hline informado & 24 & 2 & & & 3 & 1 & 3 & 2 & 2 & 37 & $1 \%$ \\
\hline \multicolumn{12}{|c|}{ Tosse } \\
\hline Sim & 4647 & 151 & 20 & 172 & 215 & 114 & 79 & 182 & 109 & 5689 & $88 \%$ \\
\hline $\begin{array}{l}\text { Não } \\
\text { Não }\end{array}$ & 591 & 20 & 2 & 23 & 55 & 11 & 13 & 21 & 9 & 745 & $12 \%$ \\
\hline informado & 12 & & & 1 & 2 & 1 & 3 & 2 & 2 & 23 & $0 \%$ \\
\hline \multicolumn{12}{|c|}{ Calafrio } \\
\hline Sim & 3110 & 102 & 8 & 49 & - & - & - & - & - & 3269 & $51 \%$ \\
\hline $\begin{array}{l}\text { Não } \\
\text { Não }\end{array}$ & 2098 & 66 & 14 & 91 & - & - & - & - & - & 2269 & $35 \%$ \\
\hline informado & 42 & 3 & & 56 & - & - & - & - & - & 101 & $2 \%$ \\
\hline \multicolumn{12}{|c|}{ Dor de garganta } \\
\hline Sim & 3126 & 81 & 9 & 63 & 71 & 31 & 9 & 53 & 20 & 3463 & $54 \%$ \\
\hline $\begin{array}{l}\text { Não } \\
\text { Não }\end{array}$ & 2084 & 90 & 13 & 130 & 198 & 92 & 83 & 146 & 96 & 2932 & $45 \%$ \\
\hline informado & 40 & & & 3 & 3 & 3 & 3 & 6 & 4 & 62 & $1 \%$ \\
\hline \multicolumn{12}{|c|}{ Dispneia } \\
\hline Sim & 2249 & 109 & 22 & 188 & 237 & 111 & 72 & 180 & 95 & 3263 & $51 \%$ \\
\hline $\begin{array}{l}\text { Não } \\
\text { Não }\end{array}$ & 2961 & 61 & 0 & 8 & 35 & 15 & 23 & 25 & 25 & 3153 & $49 \%$ \\
\hline informado & 40 & 1 & & & & & & & & 41 & $1 \%$ \\
\hline \multicolumn{12}{|c|}{ Mialgia } \\
\hline Sim & 3384 & 119 & 9 & 103 & 68 & 10 & 9 & 84 & 27 & 3813 & $59 \%$ \\
\hline $\begin{array}{l}\text { Não } \\
\text { Não }\end{array}$ & 1821 & 51 & 12 & 89 & 202 & 114 & 79 & 118 & 90 & 2576 & $40 \%$ \\
\hline informado & 45 & 1 & 1 & 4 & 2 & 2 & 7 & 3 & 3 & 68 & $1 \%$ \\
\hline \multicolumn{12}{|c|}{ Outros sintomas } \\
\hline Sim & 6599 & 189 & 20 & 156 & 448 & 171 & 136 & 376 & 228 & 8323 & $33 \%$ \\
\hline $\begin{array}{l}\text { Não } \\
\text { Não }\end{array}$ & 13693 & 489 & 65 & 460 & 356 & 204 & 148 & 238 & 131 & 15784 & $63 \%$ \\
\hline informado & 708 & 6 & 3 & 169 & 12 & 3 & 1 & 1 & 1 & 904 & $4 \%$ \\
\hline
\end{tabular}


Tabela 2. Fatores de risco

\begin{tabular}{|c|c|c|c|c|c|c|c|c|c|c|c|}
\hline & 2009 & 2010 & 2011 & 2012 & 2013 & 2014 & 2015 & 2016 & 2017 & Total & $\%$ \\
\hline \multicolumn{12}{|c|}{ Cardiopatia } \\
\hline Sim & 161 & 10 & 2 & 13 & 51 & 11 & 18 & 38 & 33 & 337 & $5,22 \%$ \\
\hline $\begin{array}{l}\text { Não } \\
\text { Não }\end{array}$ & 4704 & 158 & 19 & 173 & 217 & 114 & 76 & 162 & 86 & 5709 & $88,43 \%$ \\
\hline Informado & 385 & 3 & 1 & 10 & 4 & 1 & 1 & 5 & 1 & 411 & $6,37 \%$ \\
\hline \multicolumn{12}{|c|}{ Pneumopatia } \\
\hline Sim & 197 & 5 & 0 & 23 & 75 & 12 & 21 & 32 & 28 & 393 & $6,09 \%$ \\
\hline $\begin{array}{l}\text { Não } \\
\text { Não }\end{array}$ & 4673 & 163 & 21 & 161 & 192 & 113 & 72 & 168 & 91 & 5654 & $87,58 \%$ \\
\hline Informado & 380 & 3 & 1 & 12 & 5 & 1 & 2 & 5 & 1 & 410 & $6,35 \%$ \\
\hline \multicolumn{12}{|c|}{ Renal } \\
\hline Sim & 41 & 1 & 1 & 3 & 7 & 0 & 3 & 6 & 7 & 69 & $1,07 \%$ \\
\hline $\begin{array}{l}\text { Não } \\
\text { Não }\end{array}$ & 4820 & 166 & 20 & 181 & 261 & 125 & 91 & 194 & 112 & 5970 & $92,47 \%$ \\
\hline Informado & 389 & 4 & 1 & 12 & 4 & 1 & 1 & 5 & 1 & 418 & $6,47 \%$ \\
\hline \multicolumn{12}{|c|}{ Imunodeprimido } \\
\hline Sim & 62 & 5 & 1 & 7 & 20 & 5 & 5 & 12 & 15 & 132 & $2,04 \%$ \\
\hline $\begin{array}{l}\text { Não } \\
\text { Não }\end{array}$ & 4801 & 162 & 20 & 178 & 248 & 120 & 89 & 189 & 104 & 5911 & $91,56 \%$ \\
\hline Informado & 387 & 4 & 1 & 11 & 4 & 1 & 1 & 4 & 1 & 414 & $6,41 \%$ \\
\hline \multicolumn{12}{|c|}{ Tabagismo } \\
\hline Sim & 342 & 10 & 0 & 13 & - & - & - & - & - & 365 & $5,65 \%$ \\
\hline $\begin{array}{l}\text { Não } \\
\text { Não }\end{array}$ & 4511 & 157 & 21 & 121 & - & - & - & - & - & 4810 & $74,50 \%$ \\
\hline Informado & 397 & 4 & 1 & 62 & - & - & - & - & - & 464 & $7,19 \%$ \\
\hline \multicolumn{12}{|c|}{ Doença Metabólica Crônica } \\
\hline Sim & 58 & 4 & 0 & 5 & 27 & 9 & 8 & 17 & 18 & 146 & $2,26 \%$ \\
\hline $\begin{array}{l}\text { Não } \\
\text { Não }\end{array}$ & 4793 & 163 & 21 & 179 & 239 & 114 & 84 & 184 & 101 & 5878 & $91,05 \%$ \\
\hline Informado & 399 & 4 & 1 & 12 & 6 & 3 & 3 & 4 & 1 & 433 & $6,71 \%$ \\
\hline \multicolumn{12}{|c|}{ Outros } \\
\hline Sim & 772 & 37 & 6 & 66 & 140 & 59 & 35 & 94 & 71 & 1280 & $7,18 \%$ \\
\hline $\begin{array}{l}\text { Não } \\
\text { Não }\end{array}$ & 8478 & 296 & 36 & 254 & 1465 & 686 & 517 & 2761 & 643 & 15136 & $84,91 \%$ \\
\hline Informado & 1250 & 9 & 2 & 72 & 27 & 10 & 18 & 15 & 6 & 1409 & $7,90 \%$ \\
\hline
\end{tabular}

Os antivirais (figura 1) entraram na ficha de notificação compulsória apenas a partir de 2013. 76\% destes pacientes fizeram uso de Oseltamivir. A taxa de pacientes que não fizeram tratamento com antiviral foi de 23\%. 0,12\% fizeram uso de Zanamivir. 
Figura 1. Antivirais utilizados

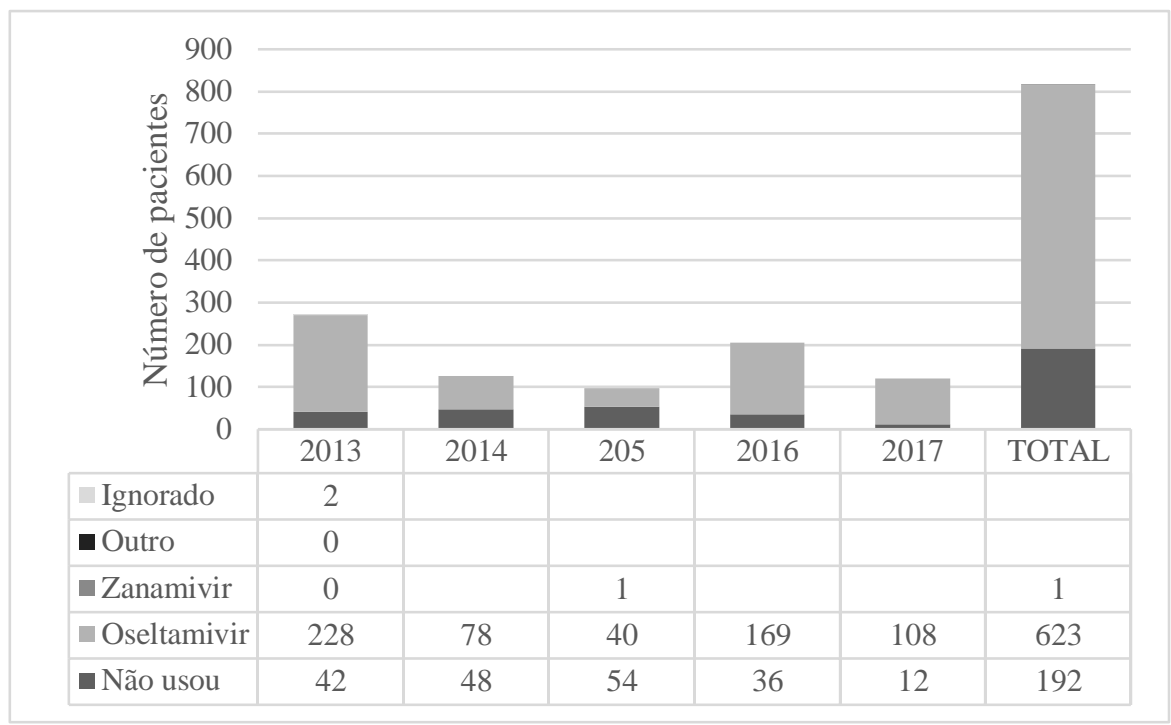

O diagnóstico etiológico resultou em uma prevalência de $52,4 \%$ do vírus Influenza $A$. Em relação ao vírus Influenza $B$ o número foi de $2 \%$. Outros agentes que foram procurados foram: subtipos de Influenza A com: H1N1 representando 4,1\% na amostra total, e não subtipado com uma incidência de $46,2 \%$, o Influenza $\mathrm{A} / \mathrm{H} 3$ sazonal teve uma incidência de $2 \%$. O Vírus Sincicial Respiratório foi diagnosticado em $9,1 \%$ dos pacientes. Outros agentes respiratórios totalizaram $20,8 \%$ dos diagnósticos. A evolução clínica de todos os casos teve em sua imensa maioria a cura como resultado final, com uma porcentagem de 95\%. O total de óbitos por SRAG foi de $4 \%$. Óbitos por outras causas foi de $1 \%$.

\section{DISCUSSÃO}

Durante os anos de 2009 a 2012 as fichas de notificação eram referentes aos casos de Influenza Humana por Novo Subtipo (Pandêmico), sendo definida como: casos com febre $>38^{\circ} \mathrm{C}$, tosse e contato próximo com indivíduos infectados em outros países, com infecção documentada nos últimos 10 dias. Em 2011, o Ministério da Saúde iniciou um processo de reorganização e ampliação da vigilância da influenza, em 2012 a portaria foi republicada e a partir de 2013 foi iniciada a notificação dos casos de SRAG. A definição de caso de SRAG é: indivíduo hospitalizado com febre, mesmo que referida, acompanhada de tosse ou dor de garganta e que apresente dispneia (MINISTÉRIO DA SAÚDE, 2015).

No ano de 2009, o Brasil apresentou um total de 50.482 casos notificados de influenza $\mathrm{A} / \mathrm{H} 1 \mathrm{~N} 1$, sendo 35.397 casos referentes à região sul. O Paraná teve a maior parcela de casos com aproximadamente $86 \%$ dos casos da região sul e $60 \%$ dos casos de todo o território nacional. Cascavel teve 5.249 casos notificados nesse mesmo ano, correspondendo a uma parcela de 17\% dos casos do estado do Paraná (MINISTÉRIO DA SAÚDE, 2012).

No Brasil, houveram 88.464 casos de SRAG notificados, com 49.459 casos na região sul, totalizando aproximadamente $56 \%$ dos casos notificados. No Paraná foram 40.015 casos, tendo a maior incidência entre todos os estados brasileiros (MINISTÉRIO DA SAÚDE, 2012). 
Tabela 3. Agentes etiológicos

\begin{tabular}{|c|c|c|c|c|c|c|c|c|c|c|c|}
\hline & 2009 & 2010 & 2011 & 2012 & 2013 & 2014 & 2015 & 2016 & 2017 & Total & $\%$ \\
\hline \multicolumn{12}{|c|}{ Influenza A } \\
\hline Positivo & 574 & 78 & 2 & 27 & 37 & 9 & 4 & 31 & 11 & 773 & $52,4 \%$ \\
\hline Negativo & - & - & - & - & 215 & 116 & 86 & 172 & 108 & 697 & $47,3 \%$ \\
\hline Inconclusivo & - & - & - & - & 0 & 0 & 0 & 0 & 0 & 0 & $0,0 \%$ \\
\hline Não realizado & - & - & - & - & 0 & 1 & 1 & 1 & 1 & 4 & $0,3 \%$ \\
\hline \multicolumn{12}{|c|}{ Subtipo Influenza A: } \\
\hline Influenza A (H1N1) & - & - & - & - & 31 & 0 & 1 & 28 & 1 & 61 & $4,1 \%$ \\
\hline Influenza A/H1 sazonal & - & - & - & - & 0 & 0 & 0 & 0 & 0 & 0 & $0,0 \%$ \\
\hline $\begin{array}{l}\text { Influenza A/H3 sazonal } \\
\text { Influenza A não }\end{array}$ & - & - & - & - & 6 & 9 & 3 & 1 & 10 & 29 & $2,0 \%$ \\
\hline subtipado & 574 & 78 & 2 & 27 & 0 & 0 & 0 & 0 & 0 & 681 & $46,2 \%$ \\
\hline $\begin{array}{l}\text { Influenza A/H3N2v } \\
\text { Outro tipo de Influenza }\end{array}$ & - & - & - & - & 0 & 0 & 0 & 0 & 0 & 0 & $0,0 \%$ \\
\hline A & - & - & - & - & 0 & 0 & 0 & 0 & 0 & 0 & $0,0 \%$ \\
\hline \multicolumn{12}{|c|}{ Influenza B } \\
\hline Positivo & - & - & - & - & 9 & 0 & 2 & 5 & 0 & 16 & $2,0 \%$ \\
\hline Negativo & - & - & - & - & 243 & 125 & 88 & 198 & 119 & 773 & $97,4 \%$ \\
\hline Inconclusivo & - & - & - & - & 0 & 0 & 0 & 0 & 0 & 0 & $0,0 \%$ \\
\hline Não relizado & - & - & - & - & 0 & 1 & 2 & 1 & 1 & 5 & $0,6 \%$ \\
\hline
\end{tabular}

\begin{tabular}{cccccccccccc} 
Positivo & 28 & 1 & 5 & 14 & 43 & 52 & 39 & 68 & 42 & 292 & $6,1 \%$ \\
Negativo & - & - & - & - & 908 & 614 & 495 & 1139 & 659 & 3815 & $79,7 \%$ \\
Inconclusivo & - & - & - & - & 0 & 0 & 0 & 0 & 0 & 0 & $0,0 \%$ \\
Não realizado & - & - & - & - & 543 & 90 & 18 & 12 & 18 & 681 & $14,2 \%$ \\
\hline
\end{tabular}

Um estudo feito em Santa Catarina, observou as fichas de notificação compulsória do Sistema de Informação de Agravos de Notificação (SINAN) de casos suspeitos de infecção pelo H1N1 em 2009, durante a epidemia, disponíveis no serviço de saúde relativas a 14 munícipios, totalizando 231.454 habitantes. Segundo o estudo, foram notificados 1.149 casos suspeitos, dos quais $560(48,7 \%)$ foram confirmados como gripe causada pelo H1N1. Em Cascavel, com a população de 286.205 pessoas, teve no ano de 20095.249 casos notificados, dos quais 474 (9\%) foram confirmados como influenza por novo subtipo viral pandêmico (SHUELTER-TREVISOL et al, 2012).

Em outro estudo, foram analisados os casos de influenza com SRAG em todo o Brasil. Os casos ocorreram entre as $16^{\mathrm{a}}$ e $33^{\mathrm{a}}$ semanas epidemiológica. Foram analisados 34.506 casos, dos quais 5.747 foram confirmados como H1N1 (OLIVEIRA et al, 2009).

$\mathrm{Na}$ figura a seguir, pode ser percebido como a variação cíclica é evidente no número de casos de Influenza. Sabe-se que após um ano de queda no número total de casos, a tendência é que o ano posterior tenha uma alta nesses números. Vários são os fatores que justificam isso. Logo, a variação cíclica mostrada neste gráfico, diz respeito ao número total de casos no Brasil (azul) e em Cascavel (alaranjado). É importante ressaltar que aqui os valores absolutos foram 
desconsiderados, sendo mostrado apenas a tendência anual dos casos, que são condizentes entre o Brasil e o município de Cascavel, entre os anos de 2010 e 2017.

Figura 2. Comparação entre números absolutos de casos Brasil x Cascavel
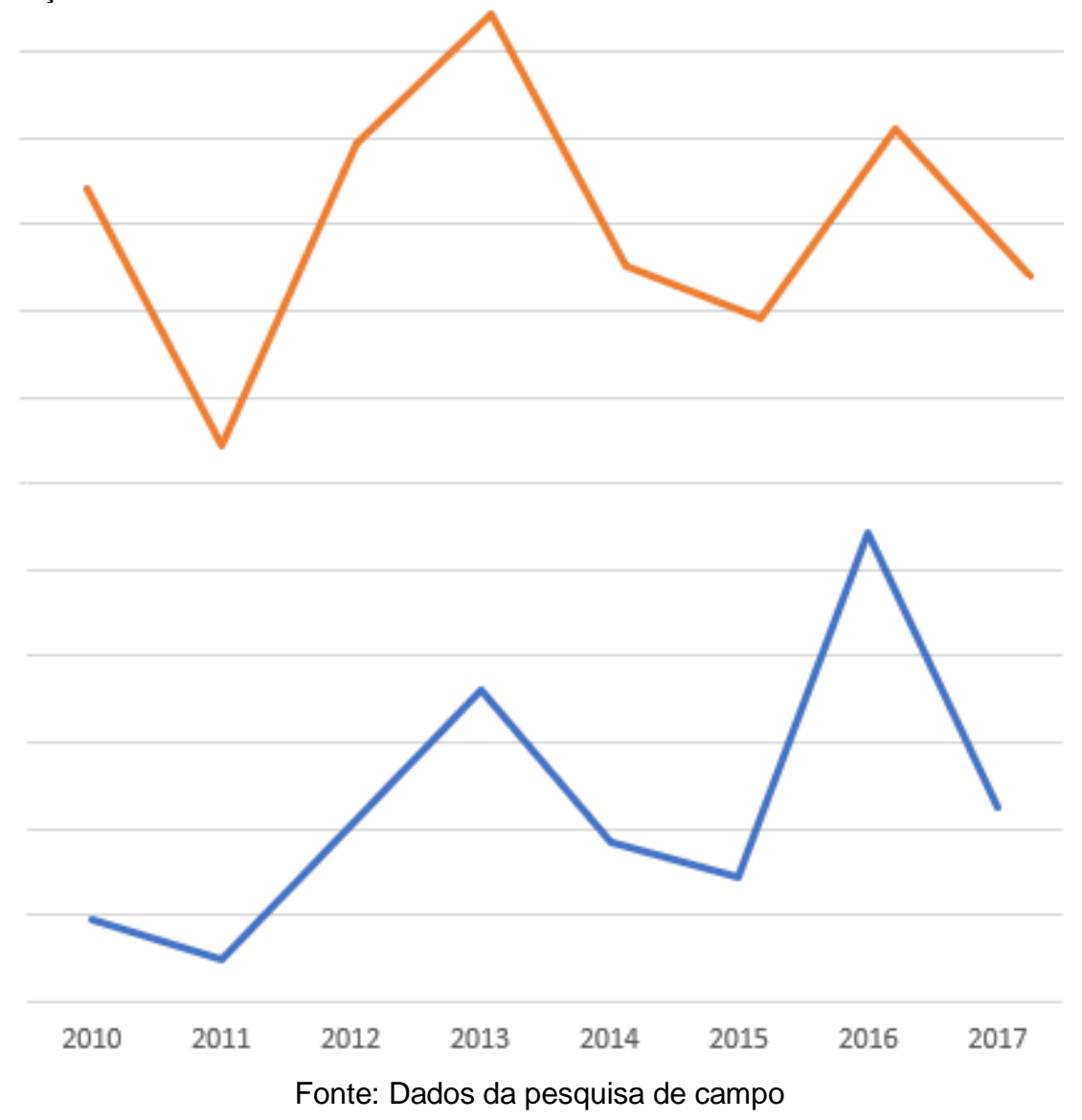

A média de idade no estudo de Oliveira (2009) foi de 26 anos, já a média encontrada em nosso estudo foi de 37,2 anos. No estudo feito por Shuelter-Trevisol (2012) a média de idade entre os casos notificados foi de 30,8 anos. Essas informações nos permitem inferir que os dados encontrados em nosso estudo, corroboram com as impressões iniciais, onde era esperado uma consonância entre os achados da literatura e o que foi encontrado nesse estudo.

Em relação a prevalência entre os sexos, Oliveira (2009) encontrou uma porcentagem de $56,5 \%$ dos casos sendo do sexo feminino. A pesquisa feita na região de Tubarão-SC, teve uma incidência de $52,3 \%$ no sexo feminino (SHUELTERTREVISOL, 2012). Essas médias foram muito próximas à encontrada em Cascavel, onde $53 \%$ dos casos ocorreram no sexo feminino.

A vacinação prévia foi em torno de apenas $12 \%$ dos casos notificados em estudo, esse valor foi próximo do encontrado por Shuelter-Trevisol (2012), com 19\% dos pacientes vacinados contra influenza previamente.

Os sintomas também sofreram alterações com a mudança nas fichas de notificação. De 2009 a 2012 os sinais e sintomas a serem observados eram: febre, tosse, calafrio, dispneia, dor de garganta, artralgia, mialgia, conjuntivite, coriza, diarreia e outros. A partir de 2013, começaram a ser notificados os casos de Síndrome Respiratória Aguda Grave, sendo os seguintes sintomas observados: febre, desconforto respiratório, tosse, dor de garganta, dispneia, mialgia, saturação de $\mathrm{O}_{2}<$ $95 \%$ e outros. 
Conforme foi observado nesse presente estudo, os sintomas mais incidentes, durante todos os anos analisados, foram tosse (88\%), febre $(85 \%)$ e mialgia $(59 \%)$. Em um estudo realizado no munícipio do Rio de Janeiro, referente ao ano de 2009 , os sintomas mais comuns, retirando-se febre, tosse e dispneia, foram mialgia $(42,7 \%)$, coriza $(39,1 \%)$, dor de garganta $(25,4 \%)$ e calafrio $(24,3 \%)$ (FELINTO et al, 2019). Nesse mesmo ano em Cascavel, os mais frequentes (retirando-se também febre, tosse e dispneia) foram, da mesma forma que no estudo do Rio de Janeiro, mialgia, dor de garganta, calafrio e coriza (FELINTO et al, 2019). Khandahker et al (2011) relataram os sintomas tosse $(84,9 \%)$, febre $(84.7 \%)$, cefaleia $(66,5 \%)$, coriza $(60,1 \%)$ e mialgia $(58,1 \%)$ como os principais. O resultado desses estudos ratifica as informações encontradas nessa presente pesquisa.

Assim como os sintomas, os fatores de risco também sofreram alterações com a alteração nas fichas de notificação. De 2009 a 2012 os fatores de risco eram considerados comorbidades (cardiopatia crônica, pneumopatia crônica, renal crônico, hemoglobinopatia, imunodeprimido, tabagismo, doença metabólica crônica e outros). A partir de 2013, são considerados como fatores de risco: pneumopatias crônicas, doença neurológica crônica, puerpério (até 42 dias do parto), doença cardiovascular crônica, doença renal crônica, obesidade, imunodeficiência/imunodepressão, síndrome de Down, doença hepática crônica, Diabetes Mellitus, e outros.

A comorbidade mais incidente foi a pneumopatia, presente em 6,09\% dos casos. O tabagismo vem em segundo lugar com 5,65\% dos casos, e a cardiopatia em terceiro com $5,22 \%$. Outros estudos encontraram as pneumopatias, seguidas pelas cardiopatias como sendo as comorbidades mais frequentes (FELINTO et al, 2019). Khandahker et al (2011) encontraram em 18\% dos casos confirmados, alguma comorbidade. Um estudo feito na Georgia, constatou que 19\% dos casos tinham alguma comorbidade, sendo a mais comum a doença cardiovascular (10\%), Diabetes Mellitus (4\%), doença respiratória (4\%) e doença neurológica (4\%) (CHAKHUNASHVILI, 2018). Foi também percebido por outro estudo, que dentre os casos que evoluíram para óbito, aproximadamente $52 \%$ apresentavam comorbidades associadas (OLIVEIRA et al, 2009).

Os antivirais utilizados integraram a ficha de notificação compulsória apenas a partir do ano de 2013. Foi apurado que $76 \%$ dos casos deste presente estudo fizeram uso de Oseltamivir. Em comparação a outro estudo onde foi analisado apenas o ano de 2009, e com somente o uso de Oseltamivir, excluindo-se outras possibilidades de antivirais, o uso foi de aproximadamente 95\% (SHUELTER-TREVISOL, 2012).

O diagnóstico etiológico é feito a partir de exames que este estudo não menciona. Teve-se a maioria dos casos sendo causada pelo vírus Influenza A $(52,4 \%)$ na somatória de todos os anos. Apenas em 2009, ano da pandemia, 10,2\% dos casos notificados tiveram o vírus $\mathrm{A} / \mathrm{H} 1 \mathrm{~N} 1$ como agente etiológico, um número muito menor do que foi encontrado por outro estudo em que $48,7 \%$ dos casos notificados, foram causados por esse vírus.

O Brasil teve 88.464 casos de SRAG notificados, dos quais $57,1 \%$ foram confirmados como Influenza do subtipo pandêmico $(\mathrm{A} / \mathrm{H} 1 \mathrm{~N} 1)$, estando esse número bem distante do que foi encontrado em Cascavel, no mesmo ano. No Paraná, ao final do ano de 2009 foram documentados 30.650 casos confirmados de $\mathrm{H} 1 \mathrm{~N} 1$, sendo $1,5 \%$ desses casos residentes em Cascavel.

Nesta presente pesquisa chegou-se à um total de $4 \%$ de óbitos, causados diretamente pela SRAG. Um estudo demonstrou que em 2009 dos 5747 casos confirmados no Brasil, 645 evoluíram para óbito, aproximadamente 11,2\%. Em outro 
estudo, também referente ao ano de 2009, teve a o índice de letalidade próximo a $2,3 \%$, quase 5 vezes maior que o encontrado em Cascavel, $0,5 \%$.

\section{CONSIDERAÇÕES FINAIS}

Durante estes 9 anos de estudo conclui-se que o perfil sociodemográfico do paciente acometido por SRAG, em Cascavel, seria: paciente do sexo feminino, mais jovem (<40 anos), que não foi imunizado contra o vírus da Influenza, o qual apresenta tosse como seu principal sintoma, devendo-se ter maior atenção com os portadores de pneumopatias crônicas.

A imunização anual contra influenza tem sido a principal medida profilática. Pensando em ações a nível de atenção primária em saúde, a execução de um programa mais eficiente de imunização é exigida. $O$ incentivo à população, para que a vacina da influenza seja realizada, promoverá a alavancagem do retorno esperado a curto prazo, tendo em vista que a imunização viabiliza segurança quanto aos desfechos desfavoráveis da doença.

A queda da mortalidade de idosos portadores de doenças respiratórias após o início da implementação da campanha vacinal pode ser explicada por algumas hipóteses como diminuição do número de casos ou da queda na incidência de casos mais graves (FRANCISCO et al, 2005).

Além da vacinação, deveriam ser realizadas campanhas de conscientização para a população em geral. A constante divulgação de informação possibilita uma melhor visão global sobre o tema, esclarecendo dúvidas e receios pré-existentes.

A imunização é uma boa prática de saúde pública e os cidadãos devem estar concordantes e cooperantes com tal prática. Ademais, diminui custos com as consequentes evoluções graves e de prognóstico ruim.

\section{REFERÊNCIAS BIBLIOGRÁFICAS}

BOGAZ C. Ministério da Saúde lança campanha nacional de vacinação contra a gripe. 2019. Disponível em <http://www.saude.gov.br/noticias/agencia-saude/45348ministerio-da-saude-lanca-campanha-nacional-de-vacinacao-contra-a-gripe $>$ Acesso em: 27 ago. 2018.

BRASIL. Ministério da Saúde. Secretaria de Vigilância em Saúde. Coordenação Geral de Doenças Transmissíveis. Vigilância sentinela de Síndrome Respiratória Aguda Grave (SRAG) em Unidade de Terapia Intensiva. Brasília, 2015.

BRASIL. Ministério da Saúde. Secretaria de Vigilância em Saúde. Informe Técnico de Influenza. Brasília, 2012.

BRASIL. Ministério da Saúde. Sistema de Informação de Agravos de Notificação. SINAN Influenza. Disponível em <http://portalsinan.saude.gov.br/sinan-influenza $>$. Acesso em: 30 set. 2018.

CHAKHUNASHVILI G, WAGNER AL, POWER LE, JANUSZ CB, MACHABLISHVILI A, KARSELADZE I, et al. Severe Acute Respiratory Infection (SARI) sentinela surveillance in the country of Georgia, 2015-2017. PLoS ONE, v.13, n.7, p. e0201497, 2018.

Disponível

em: 
$<$ https://journals. plos.org/plosone/article?id=10.1371/journal.pone.0201497> Acesso em: 24 set. 2018. https://doi.org/10.1371/journal.pone.0201497

FELINTO GM, ESCOSTEGUY CC, MEDRONHO RA. Fatores associados ao óbito dos casos graves de influenza A(H1N1)pdm09. Cadernos Saúde Coletiva, v.27, p.11-19, 2019. http://dx.doi.org/10.1590/1414-462x201900010433

FRANCISCO PMSB, DONALISIO MRC, LATTORRE MRDO. Impacto da vacinação contra influenza na mortalidade por doenças respiratórias em idosos. Rev Saúde Pública, v. 39, n.1, p.75-81, 2005. http://dx.doi.org/10.1590/S0034$\underline{89102005000100010}$

KHANDAKER G, DIERIG A, RASHID H, KING C, HERON L, BOOY R. Systematic review of clinical and epidemiological features of the pandemic influenza $A(H 1 N 1)$ 2009. Influenza and other respiratory viroses v.3, p.148-156, 2011. http://dx.doi.org/ 10.1111/j.1750-2659.2011.00199.x.

OLIVEIRA WK, CARMO EH, PENNA GO, KUCHENBECKER RS, SANTOS HB, ARAUJO WN, et al. Pandemic H1N1 influenza in Brazil: Analysis of the first 34,506 notified cases of influenza-like illness with severe acute respiratory infection (SARI). Euro Surveill v.14(42):pii=19362, 2009. https://doi.org/10.2807/ese.14.42.19362-en

PUNPANICH W, CHOTPITAYASUNONDH T. A review on the clinical spectrum and natural history of human influenza. International Journal of Infectious Diseases, v.16, p. e714-e723, 2012. https://doi.org/10.1016/j.ijid.2012.05.1025

SHUELTER-TREVISOL F, DUTRA MC, ULIANO EJM, ZANDOMÊNICO J, TREVISOL DJ. Perfil epidemiológico dos casos de gripe A na região sul de Santa Catarina, Brasil, na epidemia de 2009. Rev Panamericana de Salud Pública. Washington, D.C., Estados Unidos da América v.32, p.82-86, 2012. 